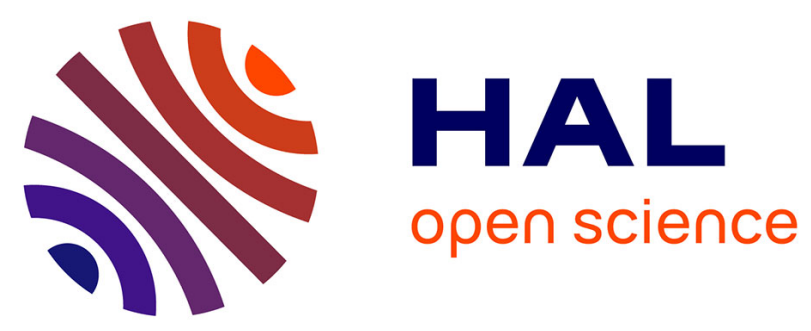

\title{
Mechanical response in amorphous and semicrystalline poly (ethylene terephtalate) and modelling in frame of quasi point defect theory
}

Emmanuelle Chabert, A. Ershad Langroudi, Catherine Gauthier, Joseph Perez

\section{- To cite this version:}

Emmanuelle Chabert, A. Ershad Langroudi, Catherine Gauthier, Joseph Perez. Mechanical response in amorphous and semicrystalline poly (ethylene terephtalate) and modelling in frame of quasi point defect theory. Plastics, Rubber and Composites, 2001, pp.56-67. 10.1179/146580101101541444 . hal00475317

\section{HAL Id: hal-00475317 https://hal.science/hal-00475317}

Submitted on 29 Nov 2019

HAL is a multi-disciplinary open access archive for the deposit and dissemination of scientific research documents, whether they are published or not. The documents may come from teaching and research institutions in France or abroad, or from public or private research centers.
L'archive ouverte pluridisciplinaire HAL, est destinée au dépôt et à la diffusion de documents scientifiques de niveau recherche, publiés ou non, émanant des établissements d'enseignement et de recherche français ou étrangers, des laboratoires publics ou privés. 


\title{
Mechanical response of amorphous and semicrystalline poly(ethylene terephthalate) and modelling in frame of quasi point defect theory
}

\author{
E. Chabert, A. Ershad Langroudi, C. Gauthier, and J. Perez
}

The thermomechanical activation of deformation in amorphous and $(38 \%$ crystalline) semicrystalline poly(ethylene terephthalate) (PET) has been investigated using dynamic mechanical tests and large strain experiments. Activation parameters for both materials are determined in the neighbourhood of the glass transition temperature using stress relaxation experiments. The complete mechanical behaviour of amorphous PET is then analysed in the frame of a molecular model or 'quasi point defect' theory. With this aim, a new method is proposed, based on only three isochronal measurements, and leading to the determination of the set parameters. This method makes it possible to reproduce the stress-strain curve over a range of temperatures, as well as the relevant activation parameters. Finally some qualitative explanations are given for the mechanical behaviour of semicrystalline PET.

\section{INTRODUCTION}

Poly(ethylene terephthalate) (PET) is extensively used today owing to its transparency and physical properties. The plastic deformation of PET, and especially its biaxial plastic deformation behaviour, is of great industrial interest in the fields of films and bottles. Moreover, PET can be considered as a model system for a fundamental study. It can be obtained either in the completely amorphous state or, after suitable thermal processing, in the semicrystalline state, with variable crystallinity ratios and morphologies. Thus, like isotactic polystyrene and polycarbonate, PET belongs to the 'low crystallinity' category of polymers proposed by Boyd. ${ }^{1}$ Such polymers can crystallise to a limited extent $(<50 \%)$.

The aim of this work was to study the linear and non-linear mechanical behaviour of amorphous and semicrystalline PET in the domain of the glass transition temperature, as well as the thermomechanical activation of deformation. For that purpose, experimental activation volume $V_{\exp }$ and activation enthalpy $\Delta H_{\exp }$ were determined with and without the presence of a crystalline phase. The whole mechanical response of amorphous PET was then analysed using a molecular approach developed in the authors' laboratory, and based on quasi point defects. ${ }^{2}$ Finally, the influence of the crystalline phase on mechanical behaviour and deformation mechanisms is discussed.

\section{EXPERIMENTS}

\section{Materials}

The amorphous PET was supplied by Goodfellow Co., France in the form of $1 \mathrm{~mm}$ thick sheets. To erase physical aging and to obtain the same isoconfigurational state for all the samples, these sheets were heated for $1 \mathrm{~h}$ at $359 \mathrm{~K}(10 \mathrm{~K}$ above the glass transition temperature $T_{\mathrm{g}}$ ) and then quenched to room temperature. The samples were characterised using wide angle X-ray scattering (WAXS) and density gradient column measurements, to ensure that no crystallisation occurred after this thermal treatment. The $38 \%$ semicrystalline PET was obtained by isothermal annealing at $430 \mathrm{~K}$ for $24 \mathrm{~h}$ and then quenching to room temperature. The crystallinity was determined at $296 \mathrm{~K}$ using a density gradient column containing ethanol and carbon tetrachloride, with densities $d_{\mathrm{A}}=1.335 \mathrm{~g} \mathrm{~cm}^{-3}$ and $d_{\mathrm{C}}=1.455 \mathrm{~g} \mathrm{~cm}^{-3}$ for the amorphous and crystalline phases, respectively. ${ }^{3}$ In the present paper, the amorphous and the 38\% crystalline PET are designated A and C38.

Wide-angle X-ray diffractograms were recorded at room temperature using a 'Rigaku-Geiger-flex' diffractometer $\left(\mathrm{Cu} K_{\alpha 1}\right.$, filtered radiation). Figure 1 shows the WAXS profiles of A and C38, obtained at a scanning rate of $0.5^{\circ} \mathrm{min}^{-1}$. The amorphous PET sample shows two halos while the semicrystalline sample exhibits three peaks characteristic of the triclinic phase. The A and C38 samples were then analysed using a DSC-7 Perkin Elmer differential scanning calorimeter at a heating rate of $10 \mathrm{~K} \mathrm{~min}^{-1}$ (thermograms are shown in Fig. 2). It can be seen that the jump in heat capacity $C_{\mathrm{p}}$ occurring at the glass transition is smaller for semicrystalline PET and is shifted towards higher temperatures. Determined from the midpoint of the endotherm, the $T_{\mathrm{g}} \mathrm{s}$ of $\mathrm{A}$ and $\mathrm{C} 38$ are 349 and $358 \mathrm{~K}$, respectively.

\section{Mechanical experiments}

\section{Dynamic mechanical analysis}

Dynamic mechanical spectrometry was performed on a home made inverted pendulum described in Ref. 4. 


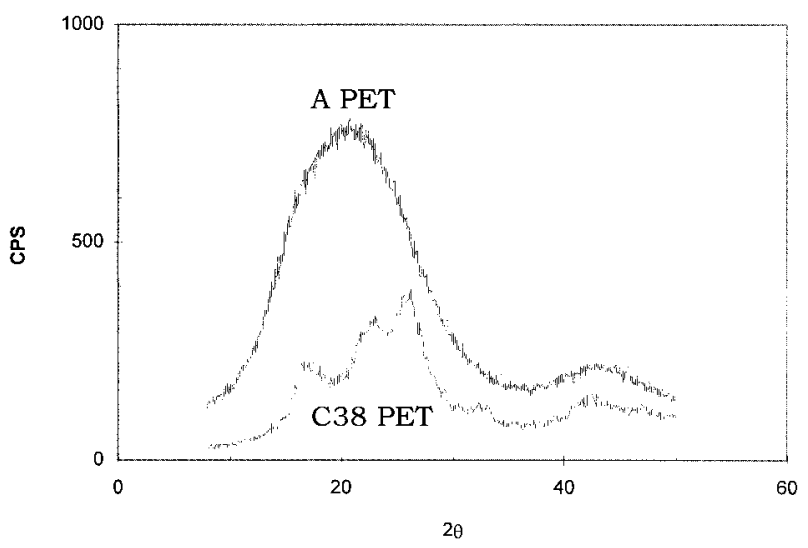

1 WAXS profiles of A and C38 PET

This device works in a helium atmosphere in the temperature range $100-700 \mathrm{~K}$ and frequency range $50 \mu \mathrm{Hz}$ to $5 \mathrm{~Hz}$. The storage $G^{\prime}$ and loss $G^{\prime \prime}$ parts of the dynamic shear modulus and hence the internal friction $\tan \phi\left(=G^{\prime \prime} / G^{\prime}\right)$ were measured as a function of temperature with a heating rate of $15 \mathrm{~K} \mathrm{~h}^{-1}$, at three frequencies $(1,0 \cdot 1$, and $0 \cdot 01 \mathrm{~Hz})$. Values of Young's modulus $E$, measured in tensile tests, were used to normalise the values of $G^{\prime}$ in the glassy plateau, based on a correspondence between the dynamic data obtained at $1 \mathrm{~Hz}$ and tensile data for a strain rate of $10^{-3} \mathrm{~s}^{-1}$.

\section{Tensile tests}

Uniaxial tensile tests were performed on an Instron 8561B machine over a temperature range of 293-373 K. Tests were conducted at a constant crosshead speed, which corresponded to an initial strain rate of $10^{-3} \mathrm{~s}^{-1}$. Samples were dumbbell shaped with typical dimensions in the gauge portion of $4 \mathrm{~mm}$ width and $25 \mathrm{~mm}$ length. The applied force was measured using a $5 \mathrm{kN}$ cell. Nominal strain $\varepsilon$ and nominal stress $\sigma$ are given by the relationships

$$
\varepsilon=\frac{L-L_{0}}{L_{0}}
$$

and

$$
\sigma=\frac{F}{S_{0}}
$$

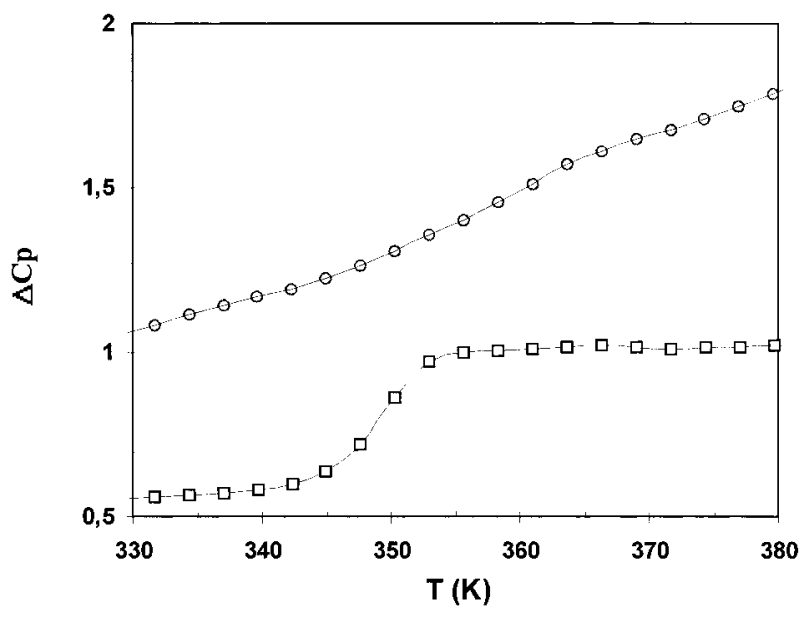

2 DSC thermograms of $A(\square)$ and C38 (O) PET (curves shifted vertically for clarity)

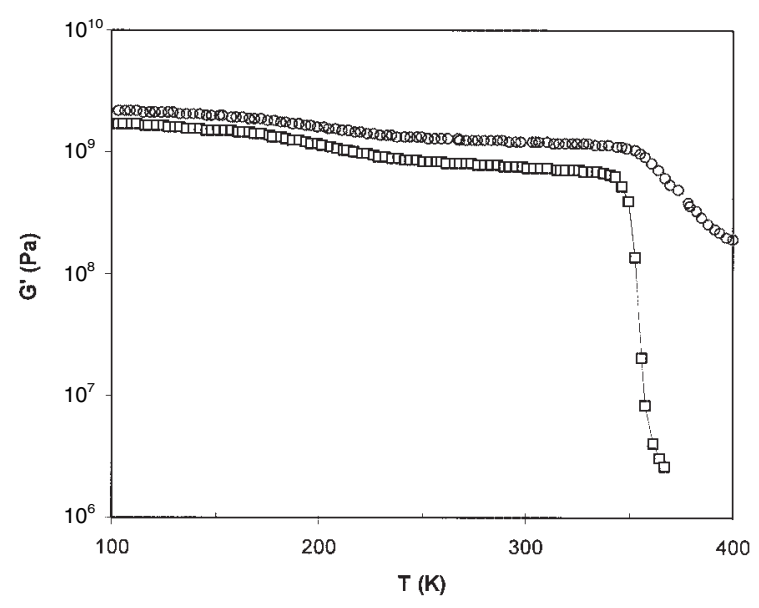

3 DMA: shear modulus of $A(\square)$ and C38 ( $\bigcirc)$ PET at $1 \mathrm{~Hz}$

where $L$ is the sample length during the test $\left(L_{0}\right.$ at time $t=0), S_{0}$ is the initial cross-sectional area of the sample, and $F$ is the applied force.

\section{Plane strain compression tests}

Plane strain compression tests were carried out on an Adhamel Lhomargy DY25 machine, between 293 and $413 \mathrm{~K}$. Parallelepiped shaped samples $(33 \times 17 \times 1 \mathrm{~mm})$ were placed between two parallel, flat polished dies (width $b$ ) and then transferred to the thermally regulated cabinet of the compression machine. The compressive force was measured using a piezoelectric gauge with a capacity of $20 \mathrm{kN}$ and an accuracy of $\pm 5 \mathrm{~N}$. The displacement $\Delta L$ of the top piston was measured with an accuracy of $\pm 0.005 \mathrm{~mm}$. Tests were carried out at a constant crosshead speed corresponding to an initial strain rate of $8 \cdot 3 \times 10^{-4} \mathrm{~s}^{-1}$.

The relationship between nominal stress $\sigma$ and nominal strain $\varepsilon$ is obtained using ${ }^{5}$

$$
\sigma=\frac{3^{1 / 2} / 2 \sigma_{\mathrm{appl}}}{1+\left(c_{\mathrm{f}} b / 4 h\right)}
$$

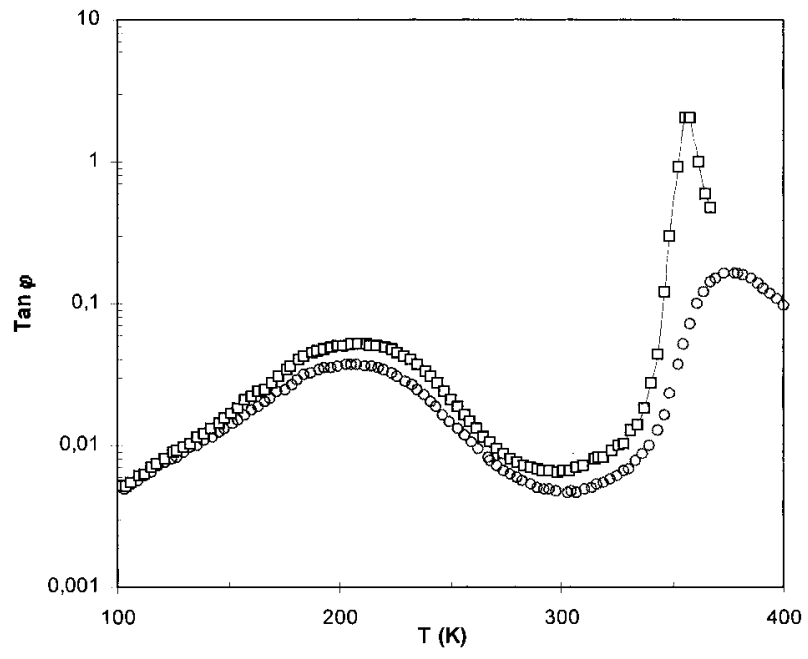

4 DMA: $\tan \phi$ of $A(\square)$ and C38 ( $\bigcirc)$ PET at $1 \mathrm{~Hz}$ 


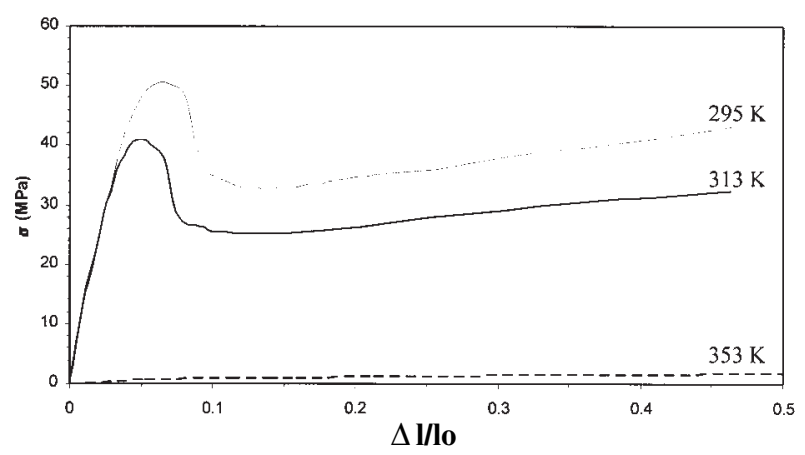

5 Tensile tests on amorphous PET; $\dot{\varepsilon}=10^{-3} \mathrm{~s}^{-1}$

and

$$
\varepsilon=\frac{2}{3^{1 / 2}} \ln \frac{h}{h_{0}}
$$

where $\sigma_{\mathrm{appl}}$ is the applied stress, $c_{\mathrm{f}}$ is the Tresca friction coefficient, and $h$ is the sample thickness under compressive stress $\left(h_{0}\right.$ at $\left.\sigma_{\text {appl }}=0\right)$.

Three pairs of dies $(b=2,3$, and $4 \mathrm{~mm})$ were used to determine $c_{\mathrm{f}}$ at ambient temperature $(0 \cdot 013)$. Molybdenum disulphide was used as a lubricant, so that friction between die and sample was considered independent of temperature, to a first approximation.

\section{RESULTS}

\section{Dynamic mechanical analysis}

Figures 3 and 4 show the variation of $G^{\prime}$ and $\tan \phi$ with temperature for $\mathrm{A}$ and $\mathrm{C} 38$. It can be seen that the characteristics of the $\beta$ relaxation (width and location of the peak temperature $T_{\beta}$ ) are similar for the amorphous and the semicrystalline PET. Additionally, the activation energy $U_{\beta}$ (determined from curves obtained at three frequencies) is the same for both materials. The presence of the crystalline phase induces only a decrease of the area of the $\beta$ relaxation peak. By contrast, the $\alpha$ relaxation is strongly affected by the crystalline phase: the relaxation widens and becomes asymmetric, the peak $T_{\alpha}$ is shifted to a higher temperature, and its height decreases.

\section{Tensile tests and plane strain experiments}

Continuing a previous study on the ductile-brittle transition of amorphous and semicrystalline PET, ${ }^{6}$

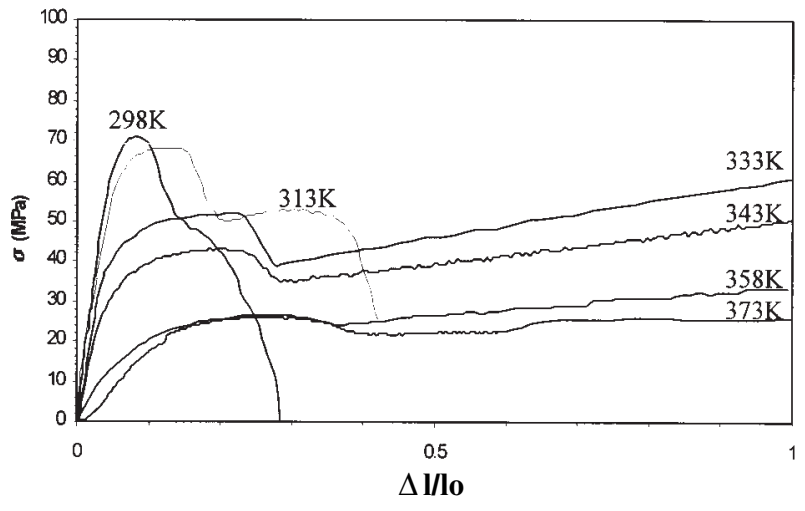

6 Tensile tests on C38 PET; $\varepsilon^{\cdot}=10^{-3} \mathrm{~s}^{-1}$

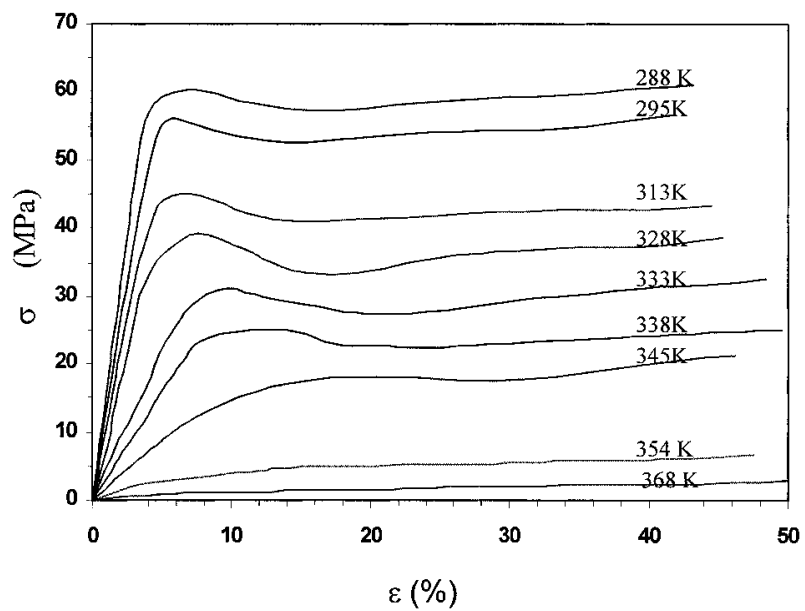

7 Plane stress experiments on amorphous PET; $\dot{\varepsilon}=8.3 \times 10^{-4} \mathrm{~s}^{-1}$

the ductile behaviour of these materials was investigated. Figures 5 and 6 show tensile tests performed on A and C38 in the temperature range 293-413 K. At temperature $T<T_{\mathrm{g}}$, the general features of the stress-strain curve for glassy polymers are observed for both amorphous and semicrystalline PET (a sharp yield point followed by a steady state plastic flow regime and a gradual strain hardening before break). In fact these curves are valid until the yield point, beyond which the deformation becomes heterogeneous due to the appearance of macro shear bands and necking. When the temperature of the test is increased, the initial slope (relaxed modulus) and the yield stress $\sigma_{\mathrm{y}}$ decrease. At $T>T_{\mathrm{g}}$, the yield peak vanishes and the stress increases monotonically with strain.

Results for plane strain experiments are presented in Figs. 7 and 8, for A and C38, respectively, near their $T_{\mathrm{g}} \mathrm{s}$. As in tensile experiments, four domains of mechanical response can be distinguished: elasticity; yield elongation; plastic deformation; and strain hardening. It can be noted that the yield peak vanishes in the presence of the crystalline phase. These large strain experiments (tensile and plane stress compression) provide insights into the mechanical behaviour of amorphous and semicrystalline PET. The relationship between yield stress and normalised tem-

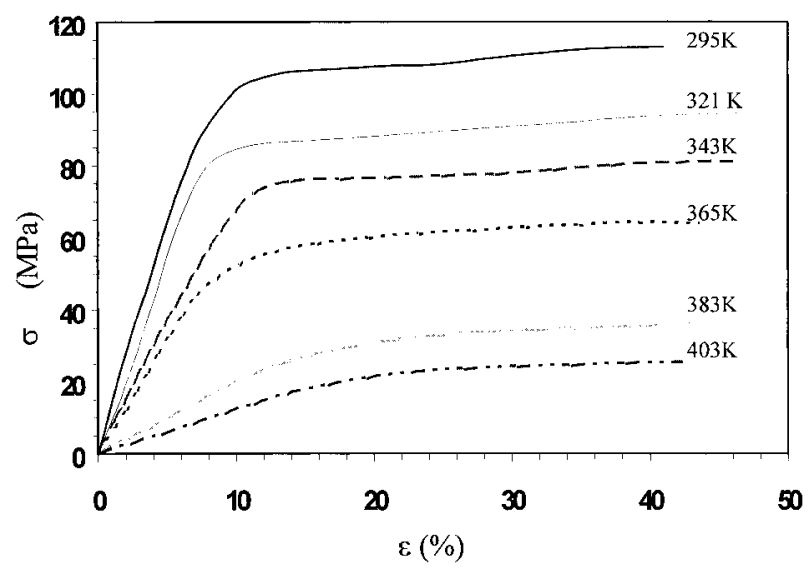

8 Plane stress experiments on C38 PET; $\dot{\varepsilon}=$ $8.3 \times 10^{-4} \mathrm{~s}^{-1}$ 


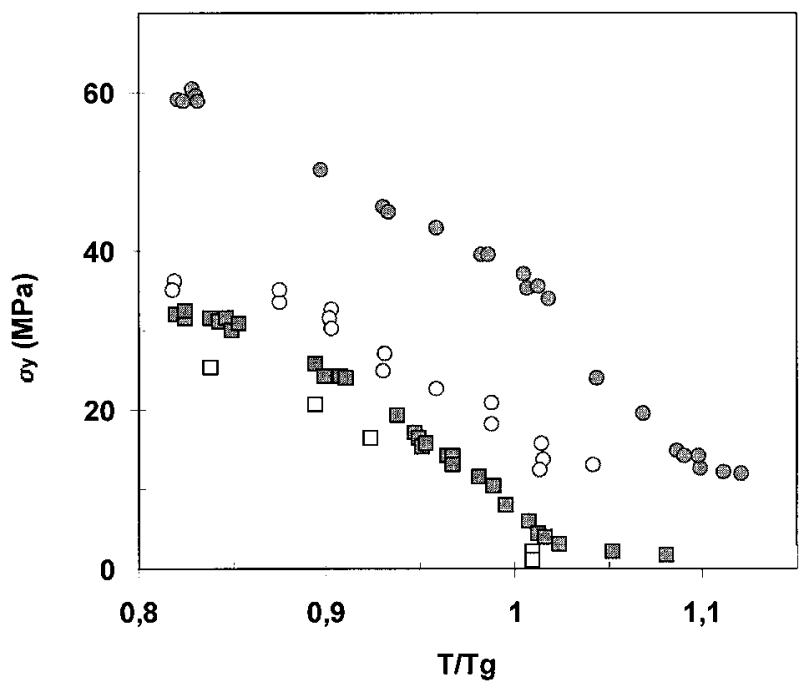

9 Evolution of yield stress $v$. normalised temperature; tensile tests: $A(\square)$ and C38 (O) PET; plane strain tests: $A(\square)$ and C38 (O) PET

perature $\left(T / T_{\mathrm{g}}\right)$ is shown in Fig. 9 (for biaxial compression experiments, values are expressed in terms of equivalent compression stress). This figure shows that the decrease of $\sigma_{\mathrm{y}}$ with increasing temperature occurs more rapidly for the amorphous PET than for the semicrystalline PET. Moreover, C38 has higher yield stress values than $\mathrm{A}$ and also exhibits much higher yield stresses in compression than in tension (by nearly a factor of 2), while A has similar yield stress values in tension and in the plane strain compression mode.

\section{Thermodynamic parameters}

To understand better the mechanisms of deformation in amorphous and crystalline phases, activation parameters were measured using plane strain tests (since in this mode the deformation appeared to be homogeneous). The thermodynamic analysis of plasticity is based on the classical relationship ${ }^{6}$

$$
\dot{\varepsilon}=\dot{\varepsilon}_{0} \exp \left(-\frac{\Delta H_{\mathrm{a}}-T \Delta S_{\mathrm{a}}}{k T}\right)
$$

with

$$
\Delta G_{\mathrm{a}}=\Delta H_{\mathrm{a}}-T \Delta S_{\mathrm{a}}=\Delta H_{0}-\sigma V_{\mathrm{a}}-T \Delta S_{\mathrm{a}}
$$

where $\dot{\varepsilon}$ is the average strain and $\dot{\varepsilon}_{0}$ is the strain at $t=0 ; \Delta G_{\mathrm{a}}$ is the free energy; $\Delta H_{\mathrm{a}}, \Delta S_{\mathrm{a}}$, and $V_{\mathrm{a}}$ are the enthalpy, the entropy, and the volume activation parameters, respectively; $\Delta H_{0}$ is the height of the enthalpy barrier to be crossed by thermal activation; and $k$ is the Boltzmann constant. In the frame of this analysis, the stress sensitivity parameter

$$
V_{\text {exp }}=k T\left(\frac{\partial \ln \dot{\varepsilon}}{\partial \sigma}\right)_{\text {T,struct }}
$$

and the experimental temperature sensitivity parameter

$$
\Delta H_{\exp }=-k T^{2}\left(\frac{\partial \ln \dot{\varepsilon}}{\partial T}\right)_{\sigma, \text { struct }}
$$

are generally measured. It is noteworthy that where

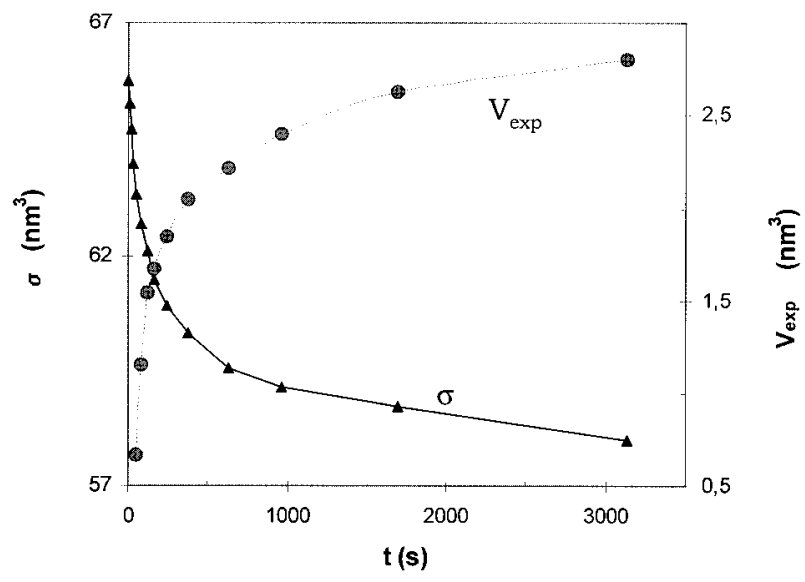

10 Stress relaxation experiment on C38 PET previously deformed up to $45 \%$ at ambient temperature, evolutions of $\sigma(\Delta)$ and $V_{\exp }(0)$ v. time

the microstructure is constant and plastic deformation results from thermomechanically induced jumps of structural units over a well defined energy barrier, these experimental values $V_{\exp }$ and $\Delta H_{\text {exp }}$ are close to the activation volume $V_{\mathrm{a}}$ and the activation enthalpy $\Delta H_{\mathrm{a}}$, respectively. However, for higher temperatures (generally considered to be above $0 \cdot 7 T_{\mathrm{g}}$ ), ${ }^{2}$ diffusion processes occur and the microstructure evolves under stress; consequently, $V_{\text {exp }}$ and $\Delta H_{\text {exp }}$ become physically meaningless.

These activation parameters were measured using stress relaxation experiments, following a method proposed by Guiu and Pratt. ${ }^{7}$ Thus, the experimental activation volume $V_{\exp }$ was determined from ${ }^{7}$

$$
\sigma(0)-\sigma(t)=\frac{k T}{V_{\exp }} \ln \left(1+\frac{t}{t_{\mathrm{p}}}\right)
$$

where

$$
t_{\mathrm{p}}=\frac{k T}{M V_{\exp }(\dot{\varepsilon})_{\mathrm{t}=0}}
$$

where $\sigma(t)$ is the equivalent stress in shearing mode at time $t(\sigma(0)$ at $t=0)$ and $M$ is the modulus of the whole assembly machine-sample.

A preliminary study was carried out to optimise the experimental conditions for determining $V_{\exp }$. This began with an investigation into the variation of $V_{\exp }$ with the values of strain at which the crosshead was stopped. It was found that $V_{\text {exp }}$ decreases from an initially infinite value, goes through a minimum in the yield region, and reaches a stable value in the plastic flow region. It was therefore decided to determine the stationary value in this latter region (corresponding to $\varepsilon \approx 45 \%$ ). The dependence of $V_{\exp }$ on relaxation time was then explored. Figure 10 shows the variations of $\sigma(t)$ and $V_{\exp }(t)$ for the semicrystalline PET compressed up to $45 \%$ at ambient temperature. It can be observed that $V_{\exp }$ increases with time and tends to a constant value $\sim 1 \mathrm{~h}$ after the beginning of stress relaxation. A time of $1 \mathrm{~h}$ of stress relaxation was then adopted in most of the experiments. In that way, $V_{\exp }$ at ambient temperature was found to be close to $2 \cdot 4 \mathrm{~nm}^{3}$, which corresponds to approximately 10 monomer units. This value, in agreement with 


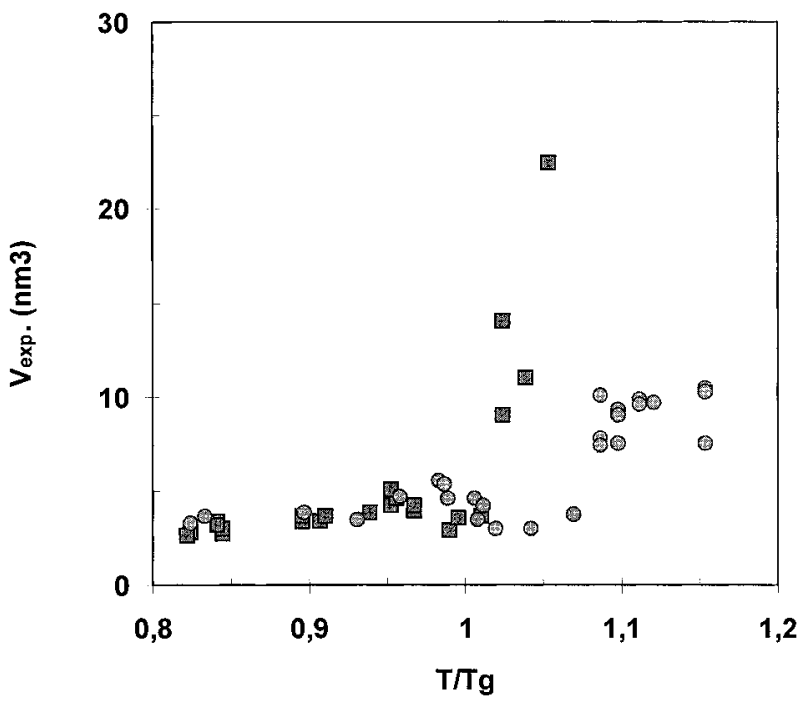

11 Evolution of $V_{\exp } v$. normalised temperature for $A(\square)$ and C38 (O) PET

other work, ${ }^{8-10}$ suggests that plastic deformation is a cooperative process involving many atoms. Above $T_{\mathrm{g}}$, the recovered stress ceases to be monotonic after a certain period of time. This might be due either to the very low stresses reached (the machine might not be sensitive enough), or to evolution of the microstructure in the case of semicrystalline PET. In these cases, the activation volume above $T_{\mathrm{g}}$ was determined for periods of less than $1 \mathrm{~h}$, using only the linear part of the $\log \sigma v \cdot \log t$ curve.

The activation energy $\Delta H_{\text {exp }}$ was estimated by noting from equations (5) and (6) that

$$
\Delta H_{\exp } \approx-T V_{\exp }\left(\frac{\partial \sigma}{\partial T}\right)
$$

The evolution of $V_{\exp }$ and $\Delta H_{\exp }$ with the normalised temperature $T / T_{\mathrm{g}}$ is represented in Figs. 11 and 12 for A and C38. It is evident from these figures that an analysis of the deformation mechanisms should be made in terms of two temperature domains:

(i) at $T<T_{\mathrm{g}}, V_{\text {exp }}$ is nearly constant while $\Delta H_{\text {exp }}$ increases linearly with temperature; moreover, amorphous and semicrystalline values are very close

(ii) at $T>T_{\mathrm{g}}, V_{\exp }$ values for amorphous PET increase dramatically as the temperature increases while $\Delta H_{\text {exp }}$ values seem to decrease; in fact, $\Delta H_{\text {exp }}$ values for $\mathrm{A}$ are so scattered around $T_{\mathrm{g}}$ that it is difficult to specify a precise temperature dependence (this will be done with the help of the modelling, see below); beyond $T / T_{\mathrm{g}} \geqslant 1 \cdot 07$, it is no longer possible to characterise A because of thermally induced crystallisation, while for C38, $V_{\exp }$ increases slightly with increasing temperature and then, like $\Delta H_{\text {exp }}$, tends to a constant value.

\section{ANALYSIS OF BEHAVIOUR OF AMORPHOUS PET}

To analyse the mechanical behaviour of the amorphous PET in small and large strain experiments, a molecular model proposed by Perez et al..$^{2,11,12}$ was

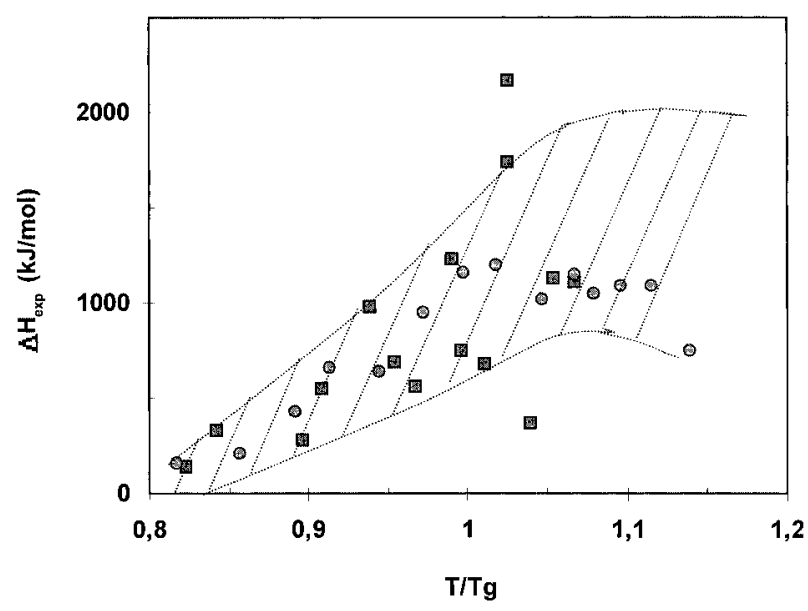

12 Evolution of $\Delta H_{\text {exp }} v$. normalised temperature for $A(\square)$ and C38 (O) PET

used, in which the macroscopic behaviour of a disordered material is related to local molecular motions. Although this molecular theory has already been applied successfully to various polymers, ${ }^{13-15}$ there is a significant improvement in the present work since the whole behaviour of the PET is modelled using parameters derived from dynamic mechanical analysis (DMA) and these parameters are determined from only three isochronal measurements (instead of from a master curve, which is much more time consuming).

\section{Modelling of linear response}

The quasi point defect approach is based on three main assumptions.

1. The amorphous material is described by a close packing of structural units in which some sites exhibit a local excess of binding enthalpy and entropy. In these sites, called quasi point defects (qpd), the molecular mobility is higher than the average molecular mobility of the material.

2. Under applied stress, some qpd are activated into 'sheared microdomains' (smd). The nucleation and growth of smd correspond to the anelastic strain (delayed reversible component) with a characteristic time $\tau_{\text {an }}$. With further deformation, smd merge irreversibly, which leads to a viscoplastic strain, with a characteristic time $\tau_{\mathrm{vp}}$.

3. The extension of smd is made via hierarchically correlated processes. Therefore, the characteristic time of those processes increases, according to the degree of correlation, from the characteristic time $\tau_{\beta}$ for an elementary movement, to the mean time $\tau_{\text {mol }}$. This time $\tau_{\text {mol }}$, corresponding to a translational motion of a structural unit over a distance comparable to its size, is given by

$$
\tau_{\mathrm{mol}}=t_{0}\left(\frac{\tau_{\beta}}{t_{0}}\right)^{1 / \chi}
$$

where processes characterised by $\tau_{\beta}$ are assumed to be the origin of the $\beta$ relaxation; $t_{0}$ is a timescale parameter; and $\chi$ is the correlation parameter. The larger $\chi$ is, the less important is the correlation effect; $\chi$ increases with the degree of disorder between 0 (perfect crystal, highest correlated movement) and 1 (perfect gas without any correlation). 
These basic ideas lead to a macroscopic compliance $J=\varepsilon / \sigma$ written as the sum of the elastic, anelastic, and viscoelastic components

$$
\begin{aligned}
& J_{\alpha}(t)=J_{\mathrm{u}}+J_{\text {an } \infty}\left\{1-\exp \left[-\left(\frac{t}{\tau_{\mathrm{rm}}}\right)^{\chi}\right]\right\} \\
& +J_{\mathrm{vp} \infty}\left(\frac{t}{\tau_{\mathrm{rm}}\left(J_{\mathrm{r}} / J_{\mathrm{an}}\right)}\right)^{\chi^{\prime}}
\end{aligned}
$$

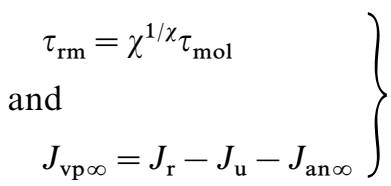

where $J_{\alpha}(t), J_{\mathrm{u}}$, and $J_{\mathrm{r}}$ are, respectively, the global, unrelaxed, and relaxed compliance associated with the $\alpha$ relaxation; $J_{\text {an } \infty}$ and $J_{\mathrm{vp} \infty}$ are, respectively, the intensity of anelastic and viscoplastic processes; and $\chi^{\prime}\left(0<\chi<\chi^{\prime} \leqslant 1\right)$ accounts for the spatial distribution of entanglements (e.g. $\chi^{\prime}=1$ for glasses). ${ }^{16}$

To compare theoretical calculations with dynamic mechanical experiments, it is convenient to convert $J_{\alpha}(t)$ (equation (11)) into the dynamic shear compliance $J_{\alpha}^{*}(i \omega)$, where $\omega$ is the pulsation and $i$ is a complex operator. A useful expression for this complex shear compliance is given by

$$
\begin{aligned}
J_{\alpha}^{*}(i \omega)= & J_{\mathrm{u}}+J_{\mathrm{an} \infty} \sum_{\mathrm{k}} \frac{g_{\mathrm{ank}}}{1+i \omega \tau_{\mathrm{ank}}} \\
& +J_{\mathrm{vp} \infty} \sum_{\mathrm{k}} \frac{g_{\mathrm{vpk}}}{1+i \omega \tau_{\mathrm{vpk}}}
\end{aligned}
$$

where $\tau_{\text {ank }}$ and $\tau_{\mathrm{vpk}}=\left(J_{\mathrm{r}} / J_{\mathrm{an}}\right) \tau_{\mathrm{ank}}$ are the characteristic times for anelasticity and viscoplasticity and $g_{\text {ank }}$ and $g_{\text {vpk }}$ are their corresponding statistical weights. In this expression, $\tau_{\mathrm{ank}}$ and $\tau_{\mathrm{vpk}}$ are distributed using an asymmetric Gumbell function ${ }^{17}$ as a result obtained using the first order Alfrey approximation. ${ }^{18}$ Indeed, according to this approximation, an extended exponential with an exponent $\chi$ (see equation (11)) is equivalent to distributions of times via a Gumbell function with $\chi$ as the width parameter. Therefore in equation (12), times $\tau_{\text {ank }}$ are distributed around $\tau_{\mathrm{rm}}$ with a Gumbell function for which the width $B_{\text {an }}$ is the correlation parameter $\chi$. Likewise, times $\tau_{\mathrm{vpk}}$ are distributed around $\tau_{\mathrm{rm}}\left(J_{\mathrm{r}} / J_{\mathrm{an}}\right)$ via a Gumbell law with a width parameter $B_{\tau v p}$ close to $\chi^{\prime}$. It can be added that this expression is of interest because it gives the distribution of times required for the extension into the non-linear domain.

Moreover, a Laplace transformation of equation (11) taking into account the rubber elasticity, leads to the following expression for the complex shear modulus ${ }^{19}$

$$
G_{\alpha}^{*}(i \omega)=G_{\mathrm{r}}+\frac{G_{\mathrm{u}}-G_{\mathrm{r}}}{1+\delta\left(i \omega \tau_{\alpha}\right)^{-\chi}+\left(i \omega \tau_{\alpha}\right)^{-\chi^{\prime}}}
$$

where $\tau_{\alpha}$ is related to $\tau_{\mathrm{rm}}$ according to

$$
\tau_{\alpha} \propto \tau_{\mathrm{rm}} \frac{J_{\mathrm{r}}}{J_{\mathrm{an} \infty}}\left(\frac{J_{\mathrm{vp} \infty}}{J_{\mathrm{u}}}\right)^{-1 / \chi^{\prime}}
$$

and $\delta$ depends on $J_{\text {an } \infty}$ via

$$
\delta \propto \frac{J_{\mathrm{an} \infty}}{J_{\mathrm{u}}}\left(\frac{J_{\mathrm{an} \infty}}{J_{\mathrm{r}}}\right)^{-\chi}\left(\frac{J_{\mathrm{vp} \infty}}{J_{\mathrm{u}}}\right)^{-\chi / \chi^{\prime}} \quad . \quad . \quad . \quad .
$$

where $\delta$ is the order of the unity, and $\tau_{\alpha}, \tau_{\mathrm{rm}}$, and $\tau_{\text {mol }}$ evolve in the same manner with temperature. Thus, in the framework of the qpd theory, linear dynamic measurements can be analysed using either an expression with the discrete distributions of relaxation times that are required for the non-linear domain (equation (13)) or the classical biparabolic expression (equation (14)), which is also of interest because all the parameters can be independently and easily determined.

The main points of interest in this model are first, the assumption that the local molecular motions occurring in the glassy state ( $\beta$ relaxation) are precursors of the large scale molecular motions responsible for the $\alpha$ relaxation; second, the macroscopic behaviour is related to a microstructural parameter $\chi$, which accounts for the concentration of disorder. This correlation parameter governs the timescales of molecular mobility and is supposed to evolve with temperature, deformation, aging, etc. Thus, when aging and deformation effects are neglected, $\chi$ has a constant value $\chi\left(T_{\mathrm{g}}\right)$ in the frozen state, whereas $\chi$ increases with temperature above $T_{\mathrm{g}}$ according to the linear first approximation

$$
\chi(T)=\chi\left(T_{\mathrm{g}}\right)+a\left(T-T_{\mathrm{g}}\right)
$$

\section{$\beta$ Relaxation}

As mentioned above, the analysis of the $\alpha$ relaxation requires a characterisation of the $\beta$ relaxation. This $\beta$ relaxation, often associated with 'crankshaft' processes, has been studied in detail in several polymers (poly(methyl methacrylate) ${ }^{20}$ poly(vinyl chloride), ${ }^{21}$ and polystyrene). ${ }^{13}$ For amorphous PET, the sub $T_{\mathrm{g}}$ relaxation appears to be very broad and slightly asymmetric (broader in the low temperature domain than in the high temperature domain). That suggests that the characteristic times $\tau_{\beta \mathrm{k}}$ are widely distributed and additionally, that the distribution law should be asymmetric with a longer tail towards shorter times. Therefore, it was decided to distribute $\tau_{\beta \mathrm{k}}$ via a Gumbell distribution of activation energy $U_{\beta \mathrm{k}}$. Thus, the dynamic compliance $J_{\beta}^{*}(i \omega)$ associated with the $\beta$ relaxation is (Orowan's relationship ${ }^{17}$ )

$$
J_{\beta}^{*}(i \omega)=\left(J_{\mathrm{u}}-J_{\mathrm{el}}\right) \sum_{\mathrm{k}} \frac{g \beta_{k}}{1+i \omega \tau_{\beta \mathrm{k}}}
$$

where $\left(J_{\mathrm{u}}-J_{\mathrm{el}}\right)$ is the strength of the $\beta$ relaxation. Times $\tau_{\beta \mathrm{k}}$ follow an Arrhenius law

$$
\tau_{\beta \mathrm{k}}=\tau_{\beta 0} \exp \left(\frac{U_{\beta \mathrm{k}}}{k T}\right) \text {. }
$$

where $\tau_{\beta 0}$ is the time of vibration (depending on activation entropy), $U_{\beta \mathrm{k}}$ is the height of the energy barrier corresponding to the $k$ process, and $g_{\beta \mathrm{k}}$ (equation (18)) is the statistical weight of the $k$ event, given by

$$
\begin{aligned}
& g_{\beta \mathrm{k}}= \\
& \frac{\exp \left\{B_{\mathrm{U} \beta}\left(U_{\beta \mathrm{k}}-\left\langle U_{\beta}\right\rangle\right)-\exp \left[B_{\mathrm{U} \beta}\left(U_{\beta \mathrm{k}}-\left\langle U_{\beta}\right\rangle\right)\right]\right\}}{\sum_{k} \exp \left\{B_{\mathrm{U} \beta}\left(U_{\beta \mathrm{k}}-\left\langle U_{\beta}\right\rangle\right)-\exp \left[B_{\mathrm{U} \beta}\left(U_{\beta \mathrm{k}}-\left\langle U_{\beta}\right\rangle\right)\right]\right\}}
\end{aligned}
$$




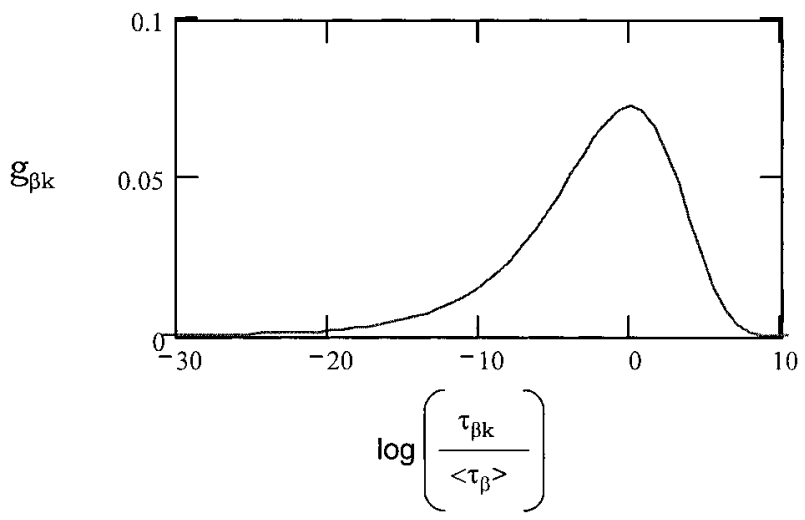

13 Distribution of $\beta$ relaxation time in amorphous PET

where $B_{\mathrm{U} \beta}$ is the width parameter of the Gumbell distribution and $\left\langle U_{\beta}\right\rangle$ is the most probable value of $U_{\beta}$. As an illustration, the calculated distribution of $\tau_{\beta \mathrm{k}}$ is plotted in Fig. 13 .

The unrelaxed modulus $G_{\mathrm{u}}$ and the elastic modulus $G_{\mathrm{el}}$ (respectively $J_{\mathrm{u}}^{-1}$ and $J_{\mathrm{el}}^{-1}$ ) are determined from the Cole-Cole diagram plotted in Fig. 14: $G_{\mathrm{u}}$ is evaluated from the inflection point between the $\alpha$ and the $\beta$ relaxation and $G_{\mathrm{el}}$ is estimated as the highest modulus value of the $\beta$ relaxation. Thus, $G_{\mathrm{u}}$ and $G_{\mathrm{el}}$ are close to 1800 and $865 \mathrm{MPa}$, respectively. The distribution width $B_{\mathrm{U} \beta}$ is chosen to account for the width of the $G^{\prime \prime}$ peak and found to be $9 \cdot 8$. The parameter $\tau_{\beta 0}$ is precisely adjusted so that experimental and calculated data for the $G^{\prime \prime}$ peak obtained at one frequency coincide, and the most probable value $\left\langle U_{\beta}\right\rangle$ is fitted to account for the shift in temperature between the three frequency curves. Thus, a value of $0.66 \mathrm{eV}$ for $\left\langle U_{\beta}\right\rangle$ (leading to an average value $U_{\beta}=0.6 \mathrm{eV}$ ) and $4 \times 10^{-17} \mathrm{~s}$ for $\tau_{\beta 0}$ are found to give the best fit. Finally, the decrease of the elastic modulus with temperature (resulting from a decrease in the mean curvature of the effective interaction potential ${ }^{17}$ ), is taken into account via

$$
J_{\mathrm{el}}(T)=J_{\mathrm{el}}\left[1+1.4 \times 10^{-3}\left(T-T_{\beta \min }\right)\right]
$$

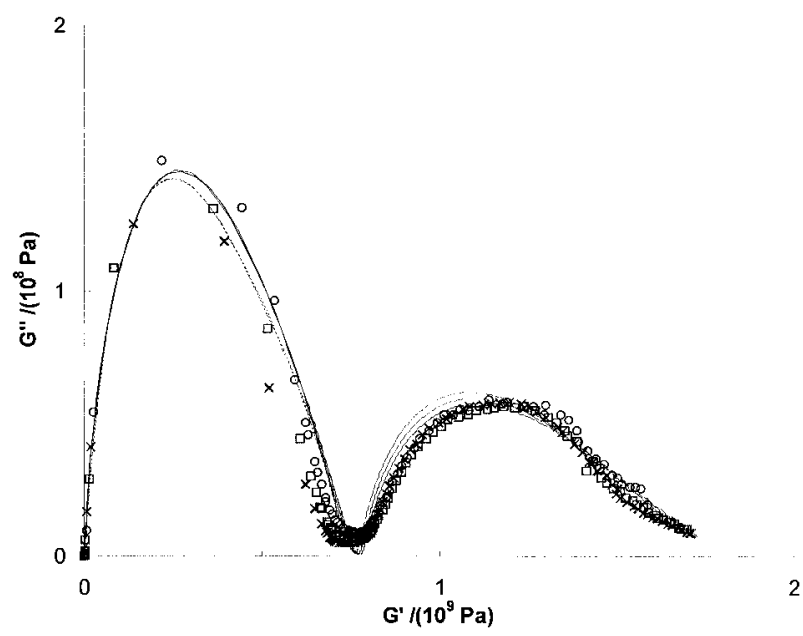

14 Cole-Cole plot of amorphous PET: $(x)$ 1, ( $\square$ ) $0 \cdot 1$, and $(\bigcirc) 0.01 \mathrm{~Hz}$ in $\beta$ and $\alpha$ relaxation domains and theoretical curves (full lines: biparabolic expression; dashed lines: discrete distribution of relaxation times)

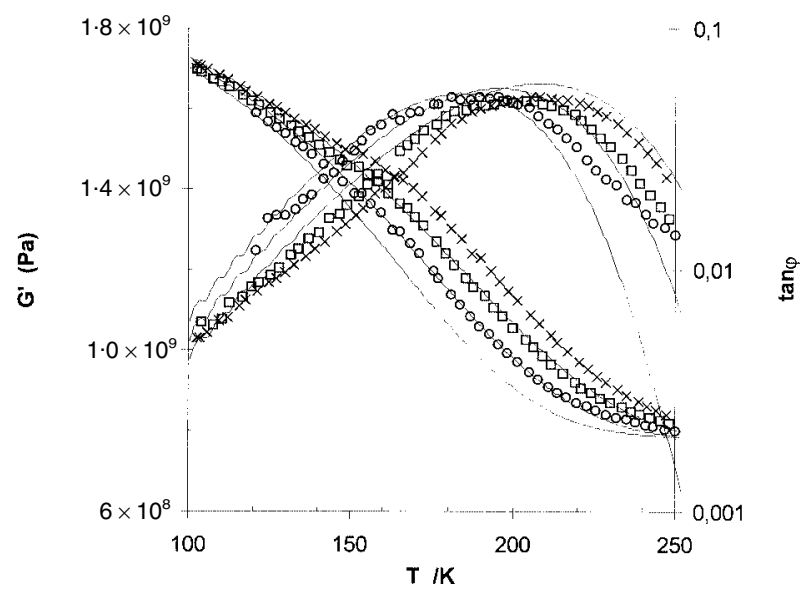

15 Isochronal measurements: $(x) 1,(\square) 0 \cdot 1$, and (○) $0.01 \mathrm{~Hz}$ in $\beta$ relaxation domain for amorphous PET; full lines: theoretical curve

where $T_{\beta \min }=95 \mathrm{~K}$ is the beginning temperature of the $\beta$ relaxation.

Finally, using these parameters, curves of $G^{\prime}$ and $\tan \phi$ in the $\beta$ relaxation domain are calculated for the three frequencies and compared with the experimental curves in Fig. 15. Figures 14-15 show a reasonably good agreement between simulated and experimental isochronal curves in the $\beta$ relaxation domain.

The contribution of the $\beta$ relaxation is then taken into account in the expression of the global compliance (equation (12) or (13)) by replacing the unrelaxed compliance of the $\alpha$ relaxation with

$$
\left.\begin{array}{l}
\quad J_{\mathrm{u}}^{*}(i \omega)=J_{\mathrm{el}}+J_{\beta}^{*}(i \omega) \\
\text { and } \\
G_{\mathrm{u}}^{*}(i \omega)=\frac{1}{J_{\mathrm{u}}^{*}(i \omega)}
\end{array}\right\} . . . .
$$

\section{$\alpha$ Relaxation}

The analysis of the $\alpha$ relaxation is made using the biparabolic expression (equation (14)). Thus, the Cole-Cole diagram provides most of the parameters: $G_{\mathrm{r}}$ is the value of the rubber plateau $(2.5 \mathrm{MPa}) ; \delta$ is adjusted to the level of the $G^{\prime \prime}$ peak (1.49); and $\chi\left(T_{\mathrm{g}}\right)$ and $\chi^{\prime}$ are determined by the angles $\theta$ and $\theta^{\prime}$ made by the plot at the high and low temperature intercepts $\left(\chi=2 \theta / \pi\right.$ and $\left.\chi^{\prime}=2 \theta^{\prime} / \pi\right)$. In fact $\chi^{\prime}$, which controls the width of the distribution of viscoplastic relaxation times, can be very precisely adjusted to the height of the $\tan \phi$ peak at one frequency. Thus, it was found that $\chi\left(T_{\mathrm{g}}\right)=0.34$ and $\chi^{\prime}=0 \cdot 88$. Parameter $t_{0}$ determines the timescale over which the global molecular motions occur: the smaller $t_{0}$ is, the closer together are the $\beta$ and $\alpha$ relaxations; $t_{0}$ is fitted so that experimental and calculated temperatures of the maximum of one frequency relaxation peak coincide $\left(t_{0}=\right.$ $2.6 \times 10^{-15} \mathrm{~s}$ ). Finally, $a$ (equation (30) below) which is the origin of the usual William-Landel-Ferry like behaviour above $T_{\mathrm{g}}$, is adjusted to account for the shift in temperature between curves obtained at the three test frequencies. The fit of the component of the $\alpha$ relaxation lying above $T_{\mathrm{g}}\left(T_{\mathrm{g}}=340 \mathrm{~K}\right.$ for $\mathrm{A}$ heated at $1 \mathrm{~K} \mathrm{~min}^{-1}$ ), requires $a \stackrel{=}{=} 0.0075$. 


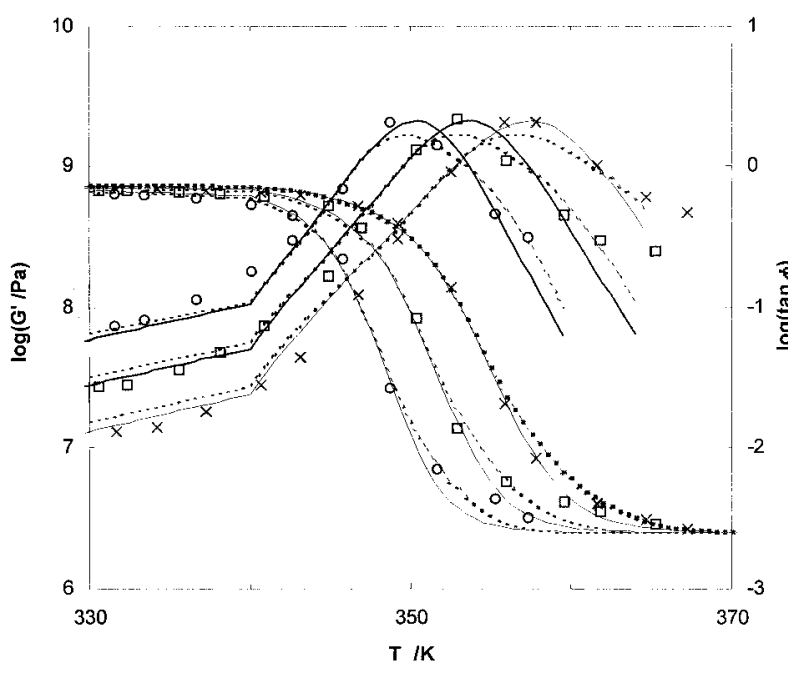

16 Isochronal curves of amorphous PET: $(x)$, $(\square) \mathbf{0 . 1}$, and $(\bigcirc) \mathbf{0 . 0 1} \mathrm{Hz}$ in $\alpha$ relaxation domain and theoretical curves (full lines: biparabolic expression; dashed lines: discrete distribution of relaxation times)

As mentioned above, the extension to the nonlinear domain is based on a discrete distribution of times (which are much more convenient for the incremental technique than the extended exponentials). Therefore, the DMA curves are fitted with equation (13), with respect to the estimations of $B_{\tau \mathrm{an}}$, $B_{\tau \mathrm{vp}}, J_{\mathrm{an} \infty}$, and $\tau_{\mathrm{rm}}$ given by equations (15) and (16). As explained, the distribution width of anelastic times $B_{\text {zan }}=\chi\left(T_{\mathrm{g}}\right)$, while the distribution width of viscoplastic relaxation times $B_{\text {tvp }}$ is close to $\chi^{\prime}$ (in fact, since the exponent $\chi^{\prime}$ of the extended exponential varies from 0 to 1 and the distribution width $B_{\tau \mathrm{vp}}$ varies from 0 to $\infty$, then as $\chi^{\prime}$ becomes smaller, so $B_{\text {tvp }}$ becomes closer to $\chi^{\prime}$ ). Therefore, the precise evaluation of $B_{\text {vvp }}$ is made on the level of the $\tan \phi$ peak. This gives $B_{\text {vvp }}=1 \cdot 17 \chi^{\prime}$. Finally, $J_{\text {an } \infty}$, the amplitude of the anelastic process, is adjusted to the level of the $G^{\prime \prime}$ peak (since $\delta$ and $J_{\text {ano }}$ are connected) and $\tau_{\mathrm{rm}}$ is evaluated to ensure a good temperature location of the relaxation peaks. Thus, for amorphous PET

$$
J_{\mathrm{an} \infty}=1 \cdot 42\left[\delta J_{\mathrm{u}}\left(J_{\mathrm{r}}\right)^{\chi}\left(\frac{J_{\mathrm{vp} \infty}}{J_{\mathrm{u}}}\right)^{\chi / \chi^{\prime}}\right]^{1 /(1-\chi)} .
$$

and

$$
\tau_{\mathrm{rm}}=2 \tau_{\alpha}\left(\frac{J_{\mathrm{an} \infty}}{J_{\mathrm{r}}}\right)\left(\frac{J_{\mathrm{vp} \infty}}{J_{\mathrm{u}}}\right)^{1 / \chi^{\prime}}
$$

It should be noted that these values are very close to the estimates given by equations (15) and (16), differing only by factors of 0.5 and 0.7 , which confirms the consistency of this method of analysis.

Finally, the calculated variations of $G^{\prime}$ and $\tan \phi$ with temperature are compared with the experimental curves in Figs. 14 and 16. Rather good agreement is observed between experimental data and simulated curves. Moreover, the biparabolic model (full lines) and the expression with a discrete distribution of relaxation times (dashed lines) gives very similar results.

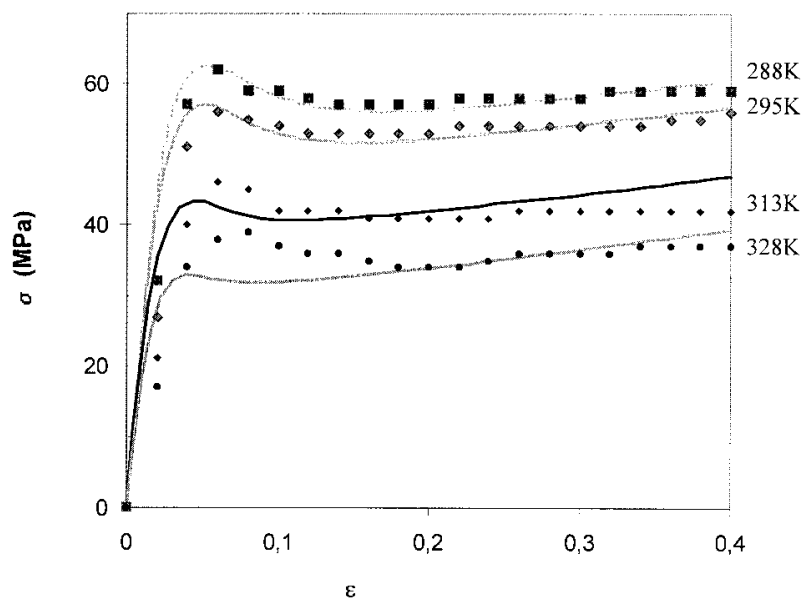

17 Plane strain experiments, $\dot{\varepsilon}=8.4 \times 10^{-4} \mathrm{~s}^{-1}$; experimental data (points) and theoretical (full lines)

\section{Modelling of plastic behaviour}

On the basis of equation (13), the qpd theory has been further extended to the non-linear domain through an incremental technique that makes it possible to determine the anelastic and viscoplastic contributions to a macroscopic deformation. The theoretical developments have been developed in detail ${ }^{22-25}$ and will only be outlined in the present paper. The evolution of the disorder (i.e. $\chi$ ) during the test is taken into account as follows

$$
\chi(T, \varepsilon)=\chi(T)+A_{\mathrm{an}} \varepsilon_{\mathrm{an}}-A_{\mathrm{vp}} \varepsilon_{\mathrm{vp}}
$$

where $A_{\text {an }}$ accounts for the increase of molecular mobility and consequently the increase of disorder as the number of smd increases. By contrast, $A_{\mathrm{vp}}$ accounts for the decrease in disorder due to chain orientation during elongation.

Moreover, under high stress and under hydrostatic pressure, the thermomechanical activation of the $\beta$ relaxation yields ${ }^{26,27}$

$$
\tau_{\beta}(\sigma)=\tau_{\beta 0} \exp \left(\frac{\left(U_{\beta}+\Omega_{\beta} P\right)\left(1-\sigma / \sigma_{0}\right)^{3 / 2}}{k T}\right)
$$

and

$$
\tau_{\mathrm{rm}}(\sigma)=\chi^{1 / \chi} t_{0}\left(\frac{\tau_{\beta}(\sigma)}{t_{0}}\right)^{1 / \chi}
$$

where $\sigma_{0}$ is the limiting yield stress necessary to surmount the energy barrier for conformational change when the temperature is $K$, i.e. $\sigma_{0} \approx G_{0} / 2 \pi$ (Frenkel argument) and $\Omega_{\beta}$ represents the sensitivity of $\beta$ movements to the hydrostatic pressure $P$. Measurements of the first pressure coefficient $\mu$ on amorphous PET $(\mu=0.05)^{28}$ show that $\Omega_{\beta}$ is $\sim 50 \AA^{3}$.

Thus, there are only three other parameters in the non-linear domain $\left(\sigma_{0}, A_{\mathrm{an}}\right.$, and $\left.A_{\mathrm{vp}}\right)$ that cannot be obtained from DMA measurements. These parameters are adjusted to match the $\sigma-\varepsilon$ data at ambient temperature: $\sigma_{0}$ is taken as being close to $260 \mathrm{MPa}$ to fit the flow stress; $A_{\text {an }}$ is determined from the height of the yield peak as 0.65 ; and $A_{\mathrm{vp}}$ is related to the strain hardening effect and is found to be $0 \cdot 1$.

At this point, it must be emphasised that there is no requirement for additional fitting parameters since 


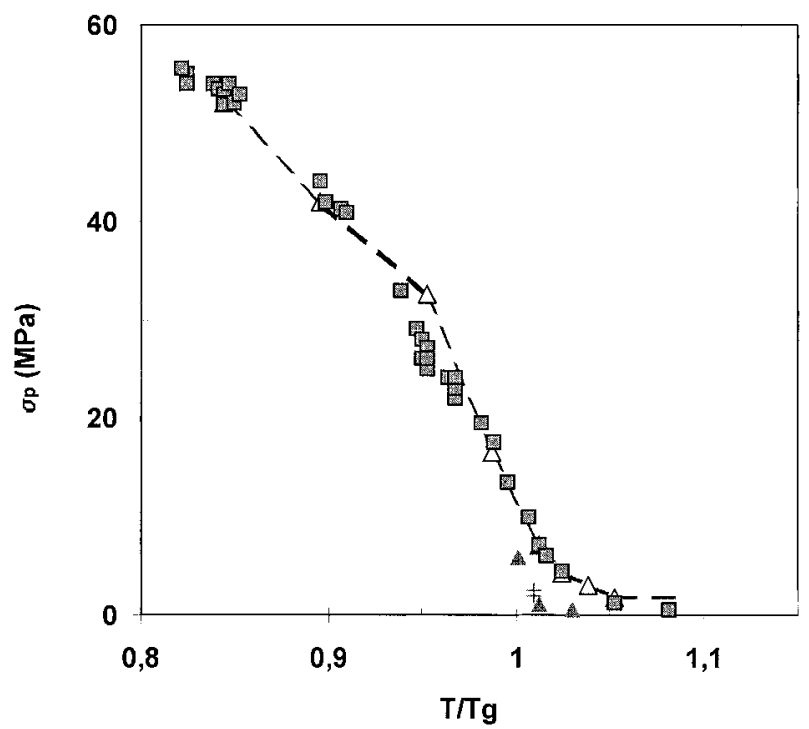

18 Plane strain experiments showing evolution of flowing stress $v$. temperature for amorphous PET (ם); theoretical with constant $\dot{\varepsilon}(\Delta)$ and with hypothesis of gradient of $\dot{\varepsilon}(-\triangle-)$; tensile experiments $(+)$

stress-strain curves have been simulated successfully at various temperatures using this unique set of parameters (see the experimental and predicted curves in Fig. 17). The results are summarised in Fig. 18, which shows the dependence of the simulated and experimental plastic flow stress $\sigma_{\mathrm{p}}$ on temperature. Below $T_{\mathrm{g}}$, the model accounts rather well for the decrease of $\sigma_{\mathrm{p}}$ with increasing temperature. Above $T_{\mathrm{g}}$ however, while simulated $\sigma_{\mathrm{p}}$ values are in good agreement with experimental tensile data, these values are lower than the values resulting from plane strain compression tests. Therefore, it is assumed that friction between die and sample is so high in the high temperature range, that the material is less mobile at the surface than it is in the centre of the sample. There might be a gradient of strain rate in the rubbery region, which leads to greater deformation of the material than would be expected. Consequently, the effective deformation rates encountered in plane strain experiments were adjusted in the sub $T_{\mathrm{g}}$ temperature range, to account for the experimental $\sigma_{\mathrm{p}}$ values.

Finally, the same set of parameters was introduced to describe the stress relaxation experiments. In these tests, the global deformation of the specimen (sum of anelastic and viscoplastic deformations) is maintained constant. Since the viscoplastic component continues to increase (i.e. some smd coalesce), elastic energy is released and the stress decreases as a function of time.

As a consequence, each $k$ smd shortens under retractive stresses related to the elastic energy stored by the dislocation loop bordering the smd $\sigma_{\text {int }}^{1}$ and also to interactions with other shear microdomains $\sigma_{\text {int }}^{2}$. The first contribution of the internal stress $\sigma_{\text {int }}^{1}$ can be evaluated by noting that when $\sigma_{\text {int }}^{1}=\sigma$, $\varepsilon_{\text {ank }}=\varepsilon_{\text {ank }_{\text {eq }}}=J_{\text {an } \infty} \sigma g_{\text {ank }}$, and hence

$$
\sigma_{\text {int }}^{1}=\frac{\varepsilon_{\text {ank }}}{J_{\text {ano } \infty} g_{\text {ank }}}
$$

The second internal stress $\sigma_{\text {int }}^{2}$, which accounts, this time, for the global smd interaction, is given by

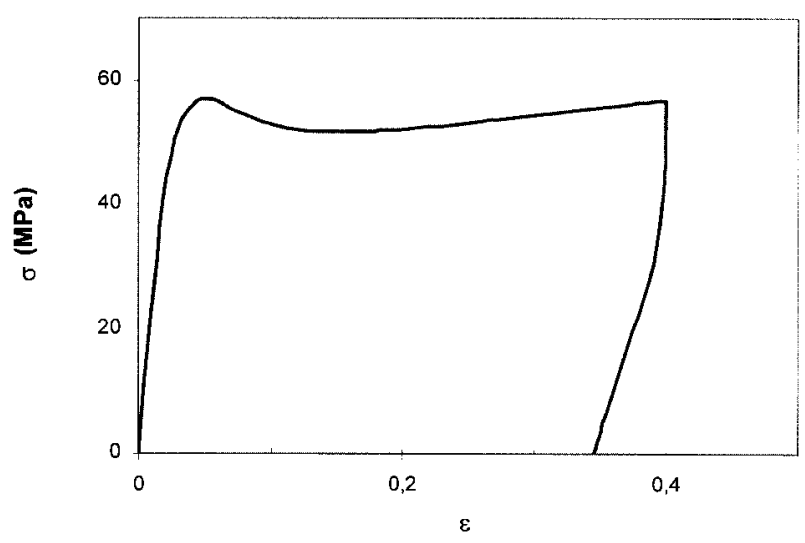

19 Plane strain experiment showing simulated loading and unloading for A PET at $295 \mathrm{~K}(\dot{\varepsilon}=$ $8.4 \times 10^{-4} s^{-1}$ )

$$
\sigma_{\text {int }}^{2}=\frac{\varepsilon_{\text {an }}}{J_{\text {an } \infty}}
$$

Finally, the anelastic deformation associated with each $k$ process decreases to its stationary value $\varepsilon_{\text {ank }_{\text {eq }}}$ according to

$$
\frac{\mathrm{d} \varepsilon_{\mathrm{ank}}}{\mathrm{d} t}=\frac{\varepsilon_{\mathrm{ank}_{\mathrm{eq}}}-\varepsilon_{\mathrm{ank}}}{\tau_{\mathrm{an}}\left(\sigma_{\mathrm{an}}\right)}
$$

where the effective stress $\sigma_{\text {an }}$ depends on $\sigma_{\text {int }}^{1}$ and $\sigma_{\mathrm{int}}^{2}$ as follows: when $\varepsilon_{\mathrm{ank}}>\varepsilon_{\mathrm{ank}_{\mathrm{eq}}}$ and $\varepsilon_{\mathrm{an}}>\varepsilon_{\mathrm{an}_{\mathrm{eq}}}$, then

$$
\sigma_{\mathrm{an}}=\left(\sigma_{\mathrm{int}}^{1}-\sigma\right) A_{\mathrm{rec}} g_{\mathrm{ank}}+\left(\sigma_{\mathrm{int}}^{2}-\sigma\right)
$$

or, when only $\varepsilon_{\text {ank }}>\varepsilon_{\text {ank }_{\text {eq }}}$, then

$$
\sigma_{\text {an }}=\left(\sigma_{\text {int }}^{1}-\sigma\right) A_{\text {rec }} g_{\text {ank }}
$$

where $A_{\text {rec }}$ accounts for the intensity of the internal stress in the relaxation process.

In the same way, the characteristic time $\tau_{\beta}\left(\sigma_{\beta}\right)$ is assisted by an effective stress $\sigma_{\beta}$ given by

$$
\sigma_{\beta}=\frac{\varepsilon_{\beta}}{\left(J_{\mathrm{u}}-J_{\mathrm{el}}\right)}-\sigma
$$

The parameter $A_{\text {rec }}$ was adjusted to fit the active unloading curve plotted in Fig. 19 to account for the residual strain observed after the release of the stress. Stress relaxation curves were then simulated and activation volume and activation enthalpy were determined following the protocol mentioned above. By comparing the experimental and simulated data on $V_{\text {exp }}\left(T / T_{\mathrm{g}}\right)$ in Fig. 20, good agreement was observed below and above $T_{\mathrm{g}}$. The simulation confirms that the activation volume of amorphous PET increases slightly with temperature below $T_{\mathrm{g}}$ and then rapidly reaches high values above $T_{\mathrm{g}}$.

It is also interesting to compare the evolution of the activation enthalpy $\Delta H_{\exp }\left(T / T_{\mathrm{g}}\right)$ with the predictions given by the theoretical approach (see Fig. 21). Below $T_{\mathrm{g}}$, both experimental and predicted values increase with temperature. In the vicinity of $T_{\mathrm{g}}$, simulated values reach a maximum and then drop when the material becomes rubbery. Thus the qpd theory makes it possible to predict the dependence of the activation enthalpy on temperature.

At low temperatures, plasticity results from local molecular movements with small energy barriers and 


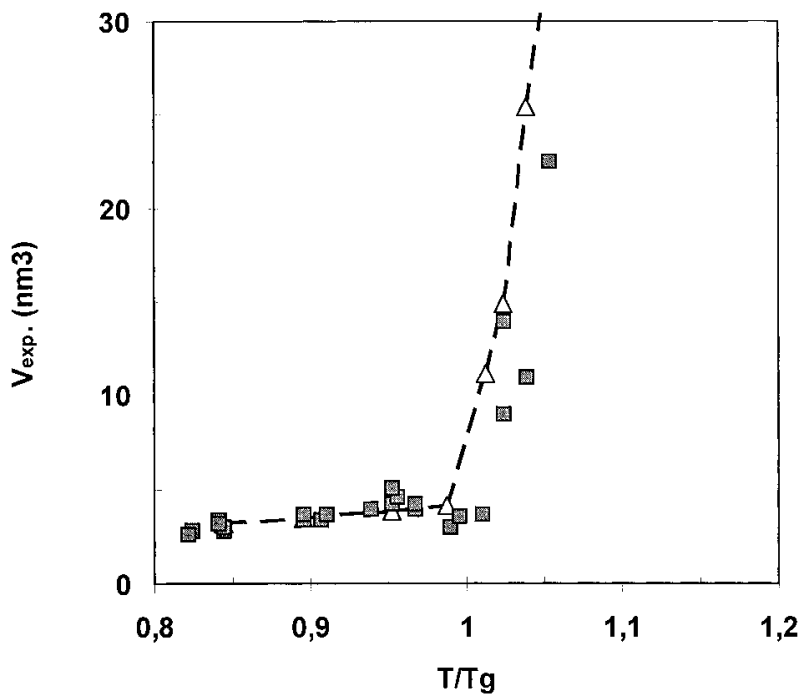

20 Evolution of apparent activation volume $V_{a} v$. normalised temperature $\left(T / T_{\mathrm{g}}\right)$ for amorphous PET ( $\square)$; theoretical $(-\triangle-)$

activation volumes. When the temperature increases, the movements become translational and therefore involve more and more structural units, leading to higher activation volumes and activation enthalpies. Above $T_{\mathrm{g}}$, the molecular mobility becomes so high that plastic deformation occurs throughout the sample ( $V_{\text {exp }}$ tends towards infinity) and the activation enthalpy decreases (the height of the barrier decreases due to increasing thermal activation).

As a conclusion, it has been shown that the qpd theory describes the main aspects of the plastic behaviour of amorphous PET. The simulation of the whole set of data has been developed in a unique frame, with only one set of parameters, deduced principally from three isochronal DMA curves. Currently the analysis seems to be one of the most successful approaches for combining all aspects of deformation behaviour in a unique selfconsistent theoretical framework. A study of the effects of crystalline phase on mechanical behaviour is considered below.

\section{ANALYSIS OF BEHAVIOUR OF SEMICRYSTALLINE PET}

\section{Linear domain}

As shown in Figs. 3 and 4, the crystalline phase does not affect both relaxations in the same way. On one hand, its principal effect on the $\beta$ relaxation is to reduce its amplitude. This dependence of the $\beta$ relaxation intensity upon crystallinity was therefore investigated for crystallinity $X_{\mathrm{c}}$ ranging from 0 to $57 \%$, and was then simulated using a mechanical reinforcement model: the auto-coherent model with three phases. ${ }^{29,30}$ Thus, taking a consistent value of crystal modulus (for instance, $4 \mathrm{GPa}$, which allows fitting of $\tan \phi$ data for $X_{\mathrm{c}}=38 \%$ ), simulations in the $\beta$ domain appeared to be in good agreement with experimental moduli $G^{\prime}$ and $G^{\prime \prime}$ for all values of crystallinity. These calculated results provide evidence that the amplitude of the $\beta$ relaxation decreases through mechanical coupling effects. Consequently, it can be concluded that the $\beta$ relaxation occurs only in the amorphous phase.

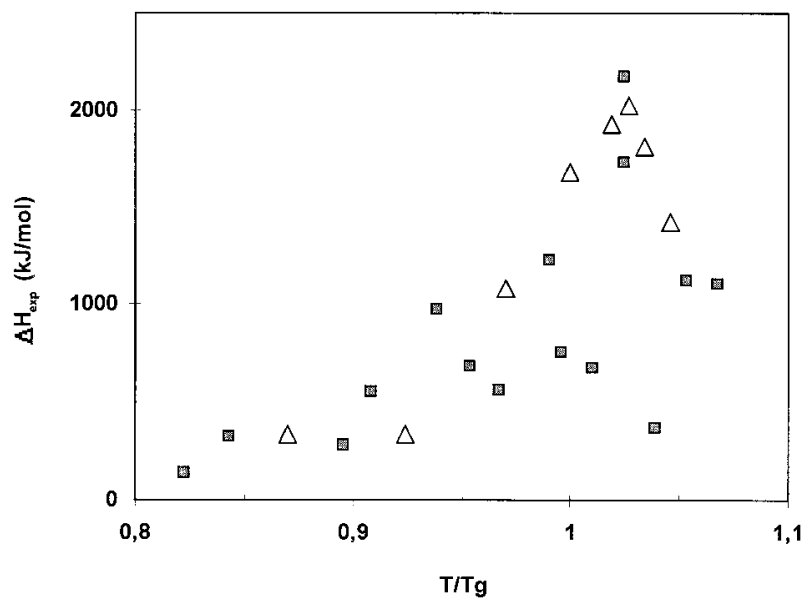

21 Evolution of activation enthalpy $\Delta H_{\exp } v$. normalised temperature $\left(T / T_{g}\right)$ for amorphous PET (ם); theoretical ( $\triangle$ )

On the other hand, the changes in the $\alpha$ relaxation with crystallinity cannot be described using the same mechanical model, since the crystalline phase causes the $\alpha$ relaxation peak not only to decrease in amplitude, but also, at the same time, to broaden and shift to a higher temperature. In the glassy plateau region, the increase of modulus can once again be accounted for by a mechanical coupling effect. In addition, owing to physical crosslinking between the two phases, crystallites may decrease the mobility of the amorphous phase, leading to the shift of $T_{\alpha}$ to a higher temperature and an increase in the shear modulus of the rubbery phase. Thus, the behaviour of the amorphous phase in semicrystalline PET seems to differ strongly from the behaviour of fully amorphous PET.

\section{Plastic behaviour}

Tensile and plane strain compression experiments performed on amorphous and semicrystalline PET can be compared by considering first the modulus values, then the yield stress and strain $\left(\sigma_{\mathrm{y}}, \varepsilon_{\mathrm{y}}\right)$ values reached at the flow threshold, and finally, the experimental activation parameters $\left(V_{\exp }\right.$ and $\left.\Delta H_{\exp }\right)$ for plastic deformation.

First, it can be observed that the moduli of A and C38, determined from plane strain compression experiments, show the same dependence upon temperature as do their shear moduli $G^{\prime}(T)$ measured in DMA tests (Fig. 3). Furthermore, the decreases in $\sigma_{\mathrm{y}}\left(T / T_{\mathrm{g}}\right)$ for amorphous and semicrystalline PET (Fig. 9) are also similar to those observed in $G^{\prime}(T)$. Hence, the crystalline phase appears to affect the modulus and the yield stress values principally by mechanical reinforcement at $T<T_{\mathrm{g}}$ and by physical crosslinking of the amorphous phase at $T>T_{\mathrm{g}}$. Moreover, it can be stated that the yield stress is related to the deformation of the amorphous phase. However, it has been noted that the difference between tensile and plane strain yield stress data is greater for semicrystalline PET. For example, at $293 \mathrm{~K}$, A reaches $52 \mathrm{MPa}$ in the tensile mode and $56 \mathrm{MPa}$ in the compression mode, while $\mathrm{C} 38$ reaches yield stresses of 77 and $120 \mathrm{MPa}$, respectively. This shift can be 
explained by hydrostatic pressure and/or morphological effects. In terms of coefficient of sensitivity to pressure, such values would lead to $\mu=0.04$ for A, which is in agreement with other work, ${ }^{26}$ and $\mu=0 \cdot 2$ for C38, which seems very high. Therefore, it is suggested that the interaction between spherulites, occurring during compressive deformation, may hinder the deformation of the amorphous phase, thus leading to higher yield stress values in plane strain tests than in tensile tests.

Finally, as highlighted by the changes in $V_{\text {exp }}\left(T / T_{\mathrm{g}}\right)$ and $\Delta H_{\exp }\left(T / T_{\mathrm{g}}\right)$, the influence of the crystalline phase on deformation mechanisms can be discussed. Above $T_{\mathrm{g}}$, is has been observed that the activation volume of the amorphous PET increases rapidly with temperature and tends towards infinity (the sample flows), while the activation volume of the semicrystalline polymer has a finite value. This suggests that at high temperatures, the semicrystalline phase might play a part in plastic deformation, via dislocation propagation. Indeed, it has been shown that the thermal generation of dislocations is possible in crystalline polymers. $^{31}$

At low temperatures however, considering that amorphous and semicrystalline PET have very similar activation volumes and activation enthalpies and that the morphology is not strongly affected by plastic deformation (DSC experiments have shown that only the smallest lamellae are modified), it can be assumed that the plastic deformation occurs principally in the amorphous phase. Thus, it may be concluded that at low temperature, the crystal phase does not modify the molecular mechanisms and only reinforces the amorphous phase, while for higher temperatures, plastic deformation occurs in both the amorphous and crystalline phases. The plastic deformation could begin in the amorphous phase located between crystalline lamellae and propagate by interlamellar slip. When the applied stress is high enough, owing to consolidation effects in the amorphous phase, crystallites might start to deform. Such a description, proposed by other authors, ${ }^{29,32-34}$ provides an explanation for the highest yield strain values of semicrystalline samples.

\section{CONCLUSIONS}

The mechanical behaviour of amorphous and 38\% semicrystalline poly(ethylene terephthalate) (PET) was investigated in small strain and large strain experiments, around their glass transition temperatures. Dynamic mechanical analysis showed that the crystalline phase induced a decrease in the intensity of the $\beta$ relaxation. Since a mechanical model (autocoherent, for instance) successfully describes such a change, it is concluded that the amplitude of the $\beta$ relaxation decreases mainly as a result of mechanical coupling effects. When it occurs in the amorphous phase of semicrystalline PET, the $\alpha$ relaxation differs strongly from the $\alpha$ relaxation of fully amorphous PET in that the size of the relaxation peak decreases by reinforcement effects and is also shifted to a higher temperature, owing to a decrease in the mobility of the amorphous phase (physical crosslinking).

For each material, the effects of temperature on yield stresses and shear moduli are similar. Thus, the elastic behaviour (observed in small and large strain experiments), is governed by both reinforcement effects and amorphous phase mobility. The shift between yield stress values in tensile and compression mode is larger for the semicrystalline PET than for the amorphous PET. Again, this can be attributed to interactions between the spherulites and the amorphous matrix.

Activation parameters were measured using stress relaxation experiments. Below $T_{\mathrm{g}}$, amorphous and semicrystalline PET exhibited the same activation volume and enthalpy. Above $T_{\mathrm{g}}$, the activation volume of amorphous PET tends towards infinity, while the activation volume of the semicrystalline PET levels off. Then at high temperatures, plastic deformation occurs in both amorphous and crystalline phases, whereas at low temperatures, plastic deformation is localised in the amorphous phase.

The whole mechanical behaviour of amorphous PET was modelled using a molecular approach proposed by Perez et al. Linear parameters were originally determined from three dynamic mechanical analysis curves obtained at various frequencies. The same set of parameters has been used successfully to describe the plane strain and stress relaxation experiments. Moreover, predicted values of activation parameters are in agreement with experiments.

\section{REFERENCES}

1. R. H. BOYD: Polymer, 1985, 26, 323-347.

2. J. PEREZ: in 'Physics and mechanics of amorphous polymers', (ed. Balkema); 1998, Rotterdam, Brookfield.

3. R. P. DAUbeny, C. W. BUnN, and C. W. BROWN: Proc. $R$. Soc. (London) A, 1954, 226, 531-542.

4. J. Y. CAVAILlE, M. SALVIA, and P. MERZEAU: Spectra 2000, 1988, 16, 37-45.

5. J. G. WiLliams: J. Mech. Eng. Sci., 1964, 6, (4), 405-417.

6. L. LAdOUCE, J. PEREZ, and R. VASSOILle: J. Phys. III France, 1996, 6, 35-54.

7. F. GUIU and P. L. PRatT: Phys. Status Solidi, 1964, 6, 111-120.

8. L. LADOUCE: PhD thesis, INSA Lyon, 1995.

9. C. P. BUCKLEY, D. C. JONES, and D. P. JONES: Polymer, 1996, 37, (12), 2403-2414.

10. A. S. ARGON and M. I. BESSONOv: Philos. Mag., 1977, 35, (4), 917-933.

11. J. Y. CAVAille, G. P. JOHARI, and J. Perez: Phys. Rev. B, Condens. Matter, 1989, 39, (4), 2411-2422.

12. J. Y. CAVAille, G. P. JOHARI, and J. PEREZ: J. Non-Cryst. Solids, 1991, 131-133, 935-941.

13. J. Y. CAVAILlE: State thesis, INSA Lyon, 1987.

14. C. GaUthieR, L. DAVID, L. LADOUCE, R. QUinSON, and J. PEREZ: J. Appl. Polym. Sci., 1996, 65, 2517-2528.

15. L. Chazeau, J. y. Cavaille, and J. Perez: J. Appl. Polym. Sci. B, 1999, 37, 2151-2164.

16. C. GAUTHIER, J. M. PELletier, L. DAVID, G. VigIER, and J. PEREZ: J. Non-Cryst. Solids, 2000, 274, 181-187.

17. J. PEREZ, J. Y. CAVAILle, and L. DAVID: J. Mol. Struct., 1999, 479, 183-194.

18. A. S. NOWICK and B. S. BERRY: in 'Anelastic relaxation in crystalline solids', Material Science Series, (ed. B. S. Berry); 1972, New York, Academic Press.

19. J. PEREZ, J. Y. CAVAILle, S. ETIENNE, and C. JOURDAN: Rev. Phys. Appl., 1988, 23, 125-135.

20. E. MUZEAU, J. PEREZ, and G. P. JOHARI: Macromolecules, 1991, 24, 4713-4723.

21. R. FLORES and J. PEREZ: Macromolecules, 1995, 28, 7171-7179. 
22. C. GAUThIER, L. DAVID, L. LADOUCE, R. QUINSON, and J. PEReZ: J. Appl. Polym. Sci., 1997, 65, (12), 2517-2528.

23. R. QUINSON: PhD thesis, INSA Lyon, 1995.

24. o. Sindt, C. GaUthier, and J. Perez: Proc. Int. Conf. on 'Deformation, yield and fracture of polymers', Cambridge, UK, May 1997, Institute of Materials, pp. 238-241.

25. L. Chazeau, J. Y. Cavaille, and J. Perez: J. Polym. Sci. B, 2000, 38, (3), 383-392.

26. M. B. mangion, J. Y. CAVAille, and J. PEREz: Philos. Mag. A, 1992, 66, (5), 773-796.

27. R. QUINSON, J. PEREZ, M. RINK, and A. PAVAN: J. Mater. Sci., 1997, 32, (5), 1371-1379.

28. A. W. CHRISTIANSEN, E. BAER, and S. V. RADCLIFFE: Philos. Mag., 1971, 24, 451-467.
29. E. HeRVE and A. ZAOUI: Eur. J. Mech. A, Solids, 1990, 9, (6), 505-515.

30. E. Herve and A. ZAOUI: Int. J. Eng. Sci., 1993, 31, (1), $1-10$.

31. J. M. HAUDIN and C. G'SELL (ed.): 'Introduction à la mécanique des polymères', 252-273; 1995, Nancy, France.

32. P. B. BOWDEN and R. J. YounG: J. Mater. Sci., 1974, 9, 2034-2051.

33. L. LIN and A. S. ARGON: Macromolecules, 1994, 27, (23), 6903-6914.

34. Z. BARTCAK, A. GALESKI, A. S. ARGON, and R. E. COHEN: Macromolecules, 1992, 25, (19), 5036-5053. 